\title{
THE ANOXÆMIC TEST FOR CORONARY INSUFFICIENCY
}

\author{
BY \\ R. W. D. TURNER AND E. V. B. MORTON \\ From the Cardiac Department, Western General Hospital, Edinburgh, and Department of Medicine, University of \\ Edinburgh \\ Received January 26, 1952
}

Physicians have long felt the need for some confirmatory test when coronary insufficiency is suspected but cannot be proved, that is to say when physical examination and resting electrocardiograms are normal. The principal problem lies in the interpretation of pain in the chest. Such a test is, of course, unnecessary apart from academic interest when the diagnosis is clear. Assistance would be particularly welcome when the history is not quite characteristic and especially perhaps in the younger age groups. Preferably too, a negative result would exclude angina as the basis for atypical pain. An objective test is much more satisfactory than a clinical impression. To this end a number of procedures have been devised and include adrenaline, pitressin, exercise and anoxæmic tests. The assessment is made on the electrocardiographic changes observed.

\section{TESTS THAT HAVE BEEN USED}

The Adrenaline Test. Levine (1930) first recommended the use of adrenaline. Typical pain was reproduced in all those suspected of having angina but in none of the controls. The $T$ waves showed an increase in height in the patients and a tendency to decrease in the controls. No changes in the S-T segment were observed. However, Katz et al. (1932) concluded that the results were too unreliable for clinical purposes and at least one group has found the test dangerous (Cottrel and Wood, 1931). It seems to have been little used since.

The Pitressin Test. Ruskin (1947) suggested the use of pitressin which is a powerful constrictor of the coronary vessels. He found good correlation with the exercise test. A positive result was taken to be a change from an upright T wave in Leads I, II, III or IV to a flat or negative one and depression of the S-T segment totalling $3 \mathrm{~mm}$. or more in Leads I, II, III or IV. There were no positive findings in normal controls and a negative test was not taken to exclude the presence of angina pectoris. However, he considered the potential risks of the test were such as to preclude its general use.

The Exercise Test. This is the most familar test and bears the merit of simplicity. It will not be discussed in detail here. The technique has varied a good deal between different observers as have criteria of abnormality. Either the patient can be given a definite amount of exertion standardized for his age, sex and weight as recommended by Master $(1942,1944)$ or else he can be exercised until pain develops or he becomes unduly breathless (Riseman, Waller, and Brown 1940). Records are taken before, immediately after and a few minutes after the exertion and the characteristic changes in the $S-T$ segment and $T$ wave, which are similar to those observed in the anoxæmic test, accurately measured. The circumstances under which the pain is naturally experienced are closely reproduced; but there are disadvantages. Electrocardiograms cannot be recorded until after the 
exertion is over, and not all patients can take sufficient exercise; moreover, though the test can be stopped should any untoward symptoms ensue, its effects may not be rapidly reversible. The deviations from normal are relatively slight and must be measured in fractions of a millimetre. Moreover, measurement is often rendered difficult by the muscle tremor and tachycardia associated with exercise. These factors militate against accuracy. However, the purpose of this paper is not to decry the exercise test, the value of which is established.

\section{The ANOXÆMIC TEST}

The anoxæmic test would appear to offer certain advantages. A mixture containing 10 per cent oxygen and 90 per cent nitrogen is administered through an anæsthetic mask. The patient is resting and, if confidence has been gained, relaxed. Records are easily made throughout the test and should pain or any other untoward symptoms occur, 100 per cent oxygen is always immediately to hand.

Greene and Gilbert (1921) were the first to study the effects of anoxæmia on the electrocardiogram in humans and Resnick in animals (1925). Ward and Wright (1929) showed that similar changes from breathing pure nitrous oxide were due to the anoxæmia produced.

The work of Kountz and Gruber (1929) was followed by their suggestion that induced anoxia might form the basis for a clinical test for coronary insufficiency and this was subsequently introduced by Rothschild and Kissin (1933). They noted depression of the S-T segments and T waves in patients with angina. The severe anoxæmia ultimately resulting from the re-breathing technique, which all early workers used, produced similar changes of lesser degree in healthy controls. They also found that such changes might be recorded during spontaneous attacks of angina pectoris. Katz's group (1934) investigated the possibilities of this test and made essentially similar observations but concluded that the results were too variable and the potential hazards too great for clinical work. Larsen in Copenhagen (1938) recommended the administration of a constant mixture containing 9 per cent oxygen in nitrogen, without rebreathing, to patients with suspected angina. He noted the lack of any constant relationship between the occurrence of pain in the chest and the electrocardiographic changes during the test. The degree of S-T deviation and T wave depression was measured and the test advocated as a practical clinical procedure. Levy $(1938,1939,1941 a$ and $b, 1946)$ has been closely associated with the development of the anoxæmia test for coronary insufficiency and has gradually evolved a standardized procedure with definite criteria of abnormality that have been accepted by the majority of subsequent workers.

The problem has been studied by numerous groups of workers since this time and general agreement reached on the type of change produced in healthy subjects and in patients known or suspected to have, coronary artery disease. Opinions have differed somewhat as to the value of the test in practice and on its relative merits compared with the exercise test but on the whole reports have been favourable. Levy and his co-workers are quite convinced and remain enthusiastic supporters of the test. Their studies have now continued for over ten years. Extensive experience has also been gained in the Mayo Clinic by Burchell's group (1948). They consider that the test has been established as having a small but useful role in the study of coronary disease. In Nylin's clinic in Stockholm $(1942,1943)$ the problem has also been thoroughly investigated and continues to be studied there by Biörck (1946 $a$ and $b$ ). Some 900 tests are made each year. Malmström (1947) also makes extensive use of the test in Sweden. Support has also come from Weintraub and Bishop in Arkansas (1947) and by Stewart's group at the New York Hospital (1948).

Riseman et al. (1940) doubt whether there are sufficient differences between normal subjects and patients to avoid errors with either the anoxic or exercise tests. Adverse criticism from Burnett's group in Colorado (1942) was counter-attacked by Patterson et al. (1942), largely on the grounds that their tests were carried out at an altitude of 6000 feet where a 10 per cent oxygen mixture is equivalent to 8 per cent at sea level. This involves a more severe test than the standard procedure and hence the results are not strictly comparable with those of other authors. Only one paper has 
come from Great Britain; that by Evans and Bourne (1940). They studied patients with definite angina rather than problem cases and gave the nitrogen mixture for rather a short time. Significant changes occurred in about half of their patients with angina who had a normal resting electrocardiogram. A very useful study of large numbers of normal people in different age groups was made by Burnett $e$ t al. (1942). They could find no correlation between the number of positive tests and increasing age such as might have been expected.

Master (1944) is satisfied that the exercise test is more reliable. Stewart et al. (1948), Biörck (1946) and Riseman et al. (1940) prefer the anoxic test and Grossman's group (1949) considers that any difference between the two is probably slight. Evans and Bourne (1940) decided the exercise test held some advantages. We are of the opinion that both tests have a part to play in difficult cases but that the anoxæmic test is preferable in the first instance.

The results of the anoxæmic test are empirical in that they are based on the comparison between the changes found in healthy persons and those known to be suffering from coronary artery disease. Varying attention has been given to factors other than anoxæmia or ischæmia which may influence the S-T segment and T waves of the electrocardiogram. Very often the test has been carried out quite unnecessarily in that the diagnosis was not really in doubt. Clearly there has been some difference of opinion as to the value and validity of the test. Owing to the need felt for assistance in certain cases we thought it would be worth while to re-evaluate it in the light of personal experience. Attention was confined to patients who presented a definite clinical problem, and the results were analysed to see how far clinical judgment was affected by the results of the test. Problem cases include those in which pain is atypical in situation, duration, quality or relationship to effort or in reponse to glyceryl trinitrate and those in which the functional factor is so predominant as to make differentiation between cardiac and non-cardiac symptoms impossible.

In this paper the effects of the anoxæmic test have been considered to be related to coronary insufficiency. However, others have used the test to assess myocardial insufficiency per se, i.e. in patients believed to have normal coronary arteries. Mannheimer (1946. 1948) is convinced of the value of this procedure as a test of myocardial insufficiency in children. He uses it almost as a routine investigation in cases of myocarditis and of acyanotic congenital heart disease. Master (1944) studied a group of adults with valvular disease and considered the test useful for assessing the degree of anoxæmia of the heart muscle during exercise. The first part of what follows deals with the practical aspects and the second with the theoretical side of the problem.

\section{TeChNique AND CRITERIA}

Cylinders containing the oxygen-nitrogen mixture can be obtained from the British Oxygen Company and a large one with enough gas for a dozen patients costs less than five shillings. An anæsthetist was usually asked to administer the mixture not because an anæsthetist is really necessary but because it enables the physician's attention to be given entirely to the patient. Great care was taken to explain the test to the patient to ensure that confidence had been fully gained. A standard Boyle's anæsthetic machine proved satisfactory and the mixture was given through an-ordinary mask at a rate of about ten litres per minute. It has usually been recommended that the gas should be given for twenty minutes but an analysis of our cases showed that ten minutes was quite sufficient and actually the cardiographic changes may regress after this time owing presumably to compensatory effects. Indeed, we have found that changes are almost always present after five minutes. We have had the advantage of using an Elmquist Triplex 4-galvanometer machine. A direct writing machine would be an obvious advantage. Records were taken after five and after ten minutes, or earlier if there were any manifestation of distress, in which case the test was immediately discontinued. 100 per cent oxygen was given for one minute at the completion of the procedure and further records taken five minutes later. If the results were negative and angina suspected, an exercise test was sometimes carried out using the same leads. 
In 1942 Levy published his revised criteria which indicated that the test should be considered positive under any of the following conditions.

1. The arithmetical sum of the S-T depressions in leads I, II, III, and IV is greater than the control by $3 \mathrm{~mm}$. or more.

2. Reversal of $T$ wave in lead I associated with $S-T$ depression in that lead of $1 \mathrm{~mm}$. or more.

3. Complete inversion of the $T$ wave in lead IV.

The above criteria were generally accepted and have been used by most workers since. They were re-assessed and re-affirmed by Weintraub and Bishop in 1947. However, Burnett (1942) on the basis of 125 tests on normal subjects had suggested that the third criterion was unreliable as 22 normal subjects showed reversal of T in CR4. These results were criticized by Patterson et al. (1942) on the grounds of the high altitude at which the tests were carried out, as mentioned above, and the possibility that many of the cases were in fact not normal. For reasons given below we are of the opinion that this third criterion is, in fact, unreliable. Criteria of abnormality should be strict because the object of these tests is not to obtain the maximum number of positives but to obtain convincing help in difficult cases.

Subjective Test. Even in the absence of cardiographic changes, this test might be considered positive if the patient experienced retrosternal pain. This, of course, throws the responsibility back on to the physician who has to interpret the subjective sensations. An experienced observer should be capable of assessing the value of such a positive test. If pain resembling angina and similar to that naturally experienced comes on with the development of anoxæmia and responds to oxygen, administered to the patient without his knowledge, then even in the absence of concomitant electrocardiographic changes the test may reasonably be considered a positive one. We have been convinced of the value of such assistance on occasion. In the anoxæmic test, pain and the electrocardiographic changes may occur quite independently.

Reactions. Naturally the patients become cyanosed. Routine arterial oxygen saturations have not been estimated because it has been established that the oxygen saturation varies considerably between different subjects breathing the same mixture (Dripps and Comroe, 1947; Penneys and Thomas, 1948; Stewart et al., 1948). Moreover, neither the occurrence of pain nor electrocardiographic changes are closely related to a certain critical level of oxygen saturation (Levy et al., 1938; Stewart et al., 1948). However, it is a reasonable suggestion that a constant level should be maintained with the help of an oximeter ( 75 per cent saturation).

The effects of anoxia on healthy persons are familiar to physiologists. Even loss of consciousness is known not to be dangerous if observed early. The few reactions which we have experienced and most of those previously reported can be explained on the basis of anxiety or occasionally cerebral anoxia. These include such symptoms as headache, dizziness, tingling, restlessness, and respiratory discomfort. Serious reactions have not been reported except in the early days in the United States when a few patients with recent infarction or cardiac failure were tested. However, a few workers have reported vaso-vagal attacks characterized by fall of blood pressure and slowing of the heart with pallor, sweating and occasional syncope. Such episodes must be very uncommon and respond to the administration of oxygen. Properly conducted, the anoxæmic test is not dangerous; reactions other than minor discomfort were only experienced in two of our patients; momentary loss of consciousness and twitching occurred, with rapid recovery on turning off the nitrogen and giving pure oxygen. The patients were unaware of the incident and there were no after-effects. Both of them were subsequently found to be anæmic. In each case the hæmoglobin was about 65 per cent. This is clearly an important point which should have been observed and taken into account. We have had no reactions in the last three years. 


\section{CONTROLS}

Although control tests have been carried out by numerous workers it was necessary to obtain our own experience and become familiar with all aspects of the procedure and to confirm the normal range for our apparatus and technique. It was not, however, considered necessary to undertake large numbers of controls in patients of all ages as this work has been thoroughly done before (Burnett et al., 1942).

The tests were all done on healthy volunteers. They consisted of members of the staff, registrars, housemen, and students. Twenty out of the 21 control tests were considered normal-the deviations from the resting records being relatively slight and within the accepted range of normal. Fig. 1 serves to demonstrate the type of record taken. Leads I, II, III, and IV were recorded simultaneously and hence it sometimes happens that a tall $R$ wave runs into the QRS complex immediately above though this does not affect the subsequent measurements. S-T segment depressions have to be added together so that an elevation at rest (as in Lead II here) must be allowed for. The isoelectric line was taken from the $P-Q$ segment and deviations were measured in millimetres. One case deserves special mention. A healthy male, aged 40 , was able to undertake strenuous exercise without pain or dyspnœa, yet total S-T depression in the anoxæmic test just amounted to $3 \mathrm{~mm}$. (Fig. 2). This is at the upper limit of the accepted normal range in that total S-T depression of $3 \mathrm{~mm}$. or more is taken to mean a pathological test. This serves as a reminder, which will be referred to later, that in any such test with an arbitrary border line between normal and abnormal, there will inevitably be some cases near the line which require caution in interpretation. In this instance there has been no adverse development during an observation period of three years.

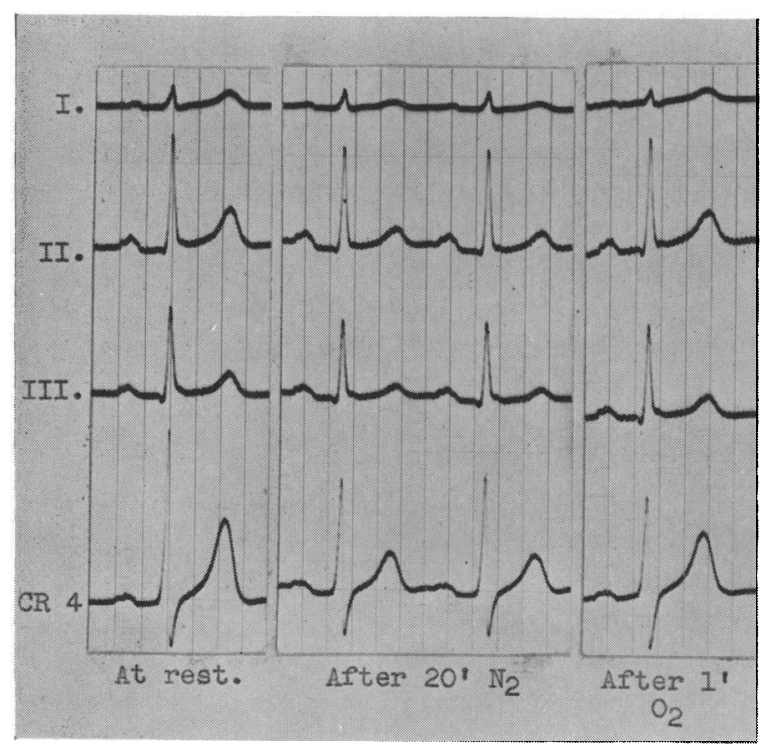

FIG. 1.-Control subject. Negative anoxæmic test.

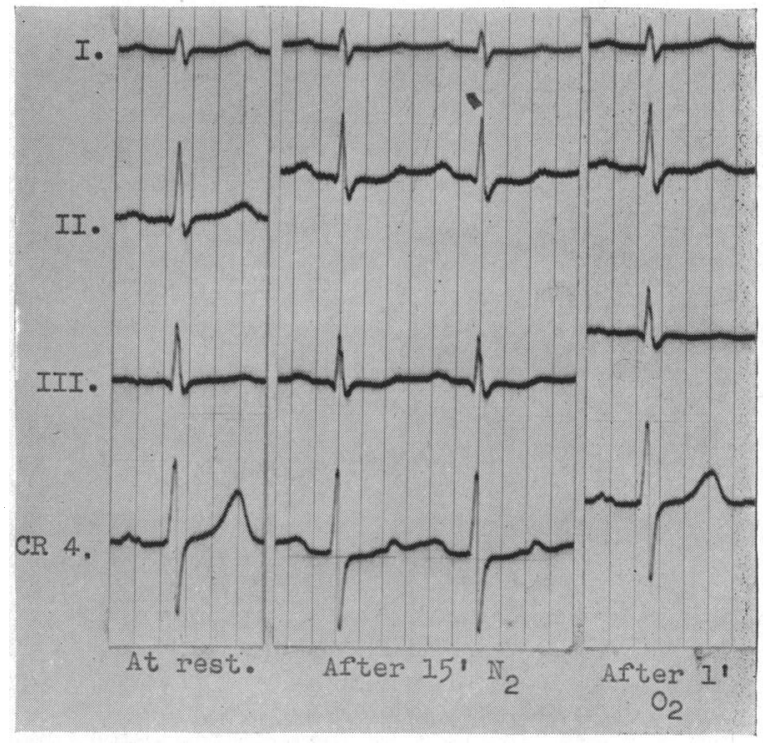

Fig. 2.-Control subject. Total S-T depression just $3 \mathrm{~mm}$. Borderline test (see text).

\section{Patients}

The findings in our cases are shown in detail in Table I and summarized in Table II. Of 30 patients examined, 14 developed abnormal cardiographic changes and 11 experienced anginal pain. In some instances objective and subjective evidence was obtained from the same individual.

From this table it will be seen that 29 out of the 30 patients have been followed up and most of them for 16-32 months. During this time it has been possible to reach a confident diagnosis on 
TABLE I

Details of Results in 30 Cases

\begin{tabular}{|c|c|c|c|c|c|}
\hline Case & Sex & $\begin{array}{l}\text { Objective } \\
\text { test }\end{array}$ & $\begin{array}{l}\text { Subjective } \\
\text { test }\end{array}$ & $\begin{array}{l}\text { Follow-up in } \\
\text { months }\end{array}$ & $\begin{array}{l}\text { Clinical assessment at end } \\
\text { of follow-up }\end{array}$ \\
\hline \multicolumn{6}{|c|}{ Patients with normal resting cardiogram } \\
\hline $\begin{array}{l}1 \\
2 \\
3 \\
4 \\
5 \\
6\end{array}$ & $\begin{array}{l}\mathbf{M} \\
\mathbf{M} \\
\mathbf{M} \\
\mathbf{F} \\
\mathbf{M} \\
\mathbf{M}\end{array}$ & $\begin{array}{l}\text { Pos. } \\
\text { Neg. } \\
\text { Pos. } \\
\text { Neg. } \\
\text { Pos. } \\
\text { Neg. }\end{array}$ & $\begin{array}{l}\text { Neg. } \\
\text { Neg. } \\
\text { Pos. } \\
\text { Neg. } \\
\text { Pos. } \\
\text { Pos. }\end{array}$ & $\begin{array}{l}32 \\
31 \\
27 \\
27 \\
24 \\
20\end{array}$ & $\begin{array}{l}\text { A.P. } \\
\text { A.P. } \\
\text { A.P. } \\
\text { No A.P. } \\
\text { M.I. in } 11 \text { th month-recovered } \\
\text { Test repeated at } 12 \text { th month. Pain repro-- } \\
\text { duced but no E.C.G. changes. Again } \\
\text { repeated } 4 \text { months later-positive ob- } \\
\text { jective and subjective test. Subsequently } \\
\text { developed M.I. }\end{array}$ \\
\hline $\begin{array}{l}7 \\
8 \\
9\end{array}$ & $\begin{array}{l}\mathrm{M} \\
\mathrm{F} \\
\mathbf{M}\end{array}$ & $\begin{array}{l}\text { Pos. } \\
\text { Neg. } \\
\text { Neg. }\end{array}$ & $\begin{array}{l}\text { Pos. } \\
\text { Neg. } \\
\text { Neg. }\end{array}$ & $\begin{array}{r}4 \\
19 \\
-\end{array}$ & $\begin{array}{l}\text { Died. M.I. } \\
\text { A.P. after } 19 \text { months } \\
\text { No follow-up available }\end{array}$ \\
\hline
\end{tabular}

Group (b)

\begin{tabular}{l|l|l|l|l|l}
\hline 10 & F & Neg. & Neg. & 28 & No A.P. \\
11 & F & Pos. & Pos. & 30 & A.P. Test repeated at 24th month-again \\
12 & positive \\
13 & F & Pos. & Pos. & 30 & A.P. \\
14 & F & Neg. & Neg. & 29 & A.P. probable \\
15 & M & Pog. & Neg. & 29 & No A.P. \\
16 & F & Pos. & Pos. & 28 & A.P. \\
17 & F & Neg. & Neg. & 24 & A.P. \\
18 & M & Neg. & Neg. & 16 & No A.P. \\
19 & F & Neg. & Neg. & 19 & No A.P. \\
20 & F & Neg. & Pos. & 18 & A.P. . \\
21 & M & Pos. & Pos. & 16 & A.P. Test repeated at 7th month-again \\
22 & F & Pos. & Neg. & 10 & positive \\
23 & M & Neg. & Neg. & 8 & No. A.P. \\
24 & F & Pos. & Neg. & 6 & A.P. . \\
25 & F & Pos. & Neg. & 6 & A.P. \\
\hline
\end{tabular}

Patients with abnormal resting cardiogram

\begin{tabular}{l|l|l|l|l|l}
\hline 26 & M & Neg. & Neg. & 29 & M.I. in 18th month-recovered \\
27 & M & Neg. & Neg. & 28 & No A.P. Believed to have neurotic pain \\
28 & F & Pos. & Pos. & 24 & A.P. \\
29 & M & Neg. & Neg. & 20 & Died. M.I. probable \\
30 & M & Pos. & Pos. & 1 & Died. No P.M. \\
\hline
\end{tabular}
A.P. $=$ Angina pectoris.
M.I. $=$ Myocardial infarction.
(a) see text.
(b) see text.

clinical grounds and it will be seen that the results of the anoxæmic test, carried out when the patient was first seen, was subsequently confirmed in 23 of the 30 patients. Six patients in whom a negative test was obtained subsequently developed angina of effort or a myocardial infarction. This suggests that no errors were made on the positive side but that a negative test does not exclude coronary disease. 
TABLE II

Summary of Results in 30 CASES AND 21 Controls

\begin{tabular}{llcc}
\multicolumn{4}{c}{ OBJECTIVE TEST* } \\
Positive & Negative \\
Controls & 21 & 1 & 20 \\
Patients & 30 & 14 & 16 \\
& & & \\
& SUBJECTIVE & TEST (ANGINAL PAIN) \\
Controls & 21 & Positive & Negative \\
Patients & 30 & 0 & 21 \\
& & 11 (9 E.C. positive) & 19 \\
& *Cardiographic criteria of Levy (see text)
\end{tabular}

In 25 of these 30 cases, resting electrocardiograms were quite normal Standard limb leads and at least three (usually six) chest leads were recorded In none of the cases presented was the diagnosis considered certain. Each had atypical features. The degree of clinical doubt varied from case to case. Objective evidence was preferred to a complaint of pain and attention was only paid to unequivocal changes. On the whole the results of the anoxæmic tests fitted in with our clinical impressions and positive results were obtained when most expected. Nevertheless the information was of definite value in these positive cases in that a firm diagnosis could be made. In some of our patients considerable differences of opinion had been expressed. For purpose of analysis the patients should really be divided into two groups. Group $(a)$ Table I consisted of cases in whom angina was really suspected though some unusual feature was present and all other methods of examination were negative. It was in this group in particular that we gained our initial experience. In this Group (a) 4 out of 9 patients developed abnormal cardiograms and 3 of these 4 also experienced anginal pain. One patient developed pain but no graphic changes. Group (b) consisted of more difficult problem cases; 8 out of 16 patients developed abnormal records and 4 of these 8 also experienced pain. One patient developed pain but no cardiographic changes.

It is doubtful how much significance should be attached to negative results. A patient with a negative test may subsequently develop myocardial infarction. This happened to 2 of our patients, one 18 and one 20 months later. It may well be that a negative test does suggest that the symptoms complained of at the time are not of ischæmic origin. However, caution is obviously required in this group and a dogmatic opinion cannot be reached. A negative test can give no more than guarded reassurance to the physician. Clearly there is a varying balance between the factors responsible for the accumulation of metabolites or whatever is the ultimate mechanism in the production of pain and the increased coronary blood flow resulting from anoxæmia particularly as regards the capacity of an anastomotic circulation to nourish the pain-producing area. In addition to the direct effects of anoxæmia on the heart, there must be considered the indirect effects on the cardiovascular system from stimulation of the respiratory and nervous systems, resulting in variations of ventilation, heart rate, blood pressure, and the work done by the heart. Moreover, as referred to above, the arterial oxygen saturation varies considerably in different individuals and from time to time in the same individual breathing a constant low oxygen mixture.

Five of the 30 patients had abnormal records at rest and a history suggesting past myocardial infarction. Patients with recent infarction, of course, were not examined. Nevertheless the pain complained of was not characteristic and difficult to interpret. Patients in this group were usually neurotic or at least an associated functional factor was thought to be predominant. In 2 of these 5 cases, a positive objective result was obtained-that is to say ischæmic changes were superimposed on the previous abnormality and both of them developed angina during the test. The other 3 tests in this group of 5 cases were negative. We feel that valuable information was also obtained in these two positive cases. In spite of the presence of organic heart disease it had been considered that the pain was probably due to anxiety. Four cases will now be considered by way of illustration. 
Case 21. A soldier, aged 36. Two years history of epigastric pain related to exertion, especially after meals. Long periods of remission. Ischæmic pain suspected but atypical features present. In view of relatively young age and the fact that he was a regular army officer a definite diagnosis was particularly desirable. Clinical examination, X-ray and cardiograms negative. Barium meal normal. No hiatus hernia. Positive anoxæmic test (total S-T depression $=6 \frac{1}{2} \mathrm{~mm}$. Fig. 3; Case 21). Follow-up confirmed diagnosis.

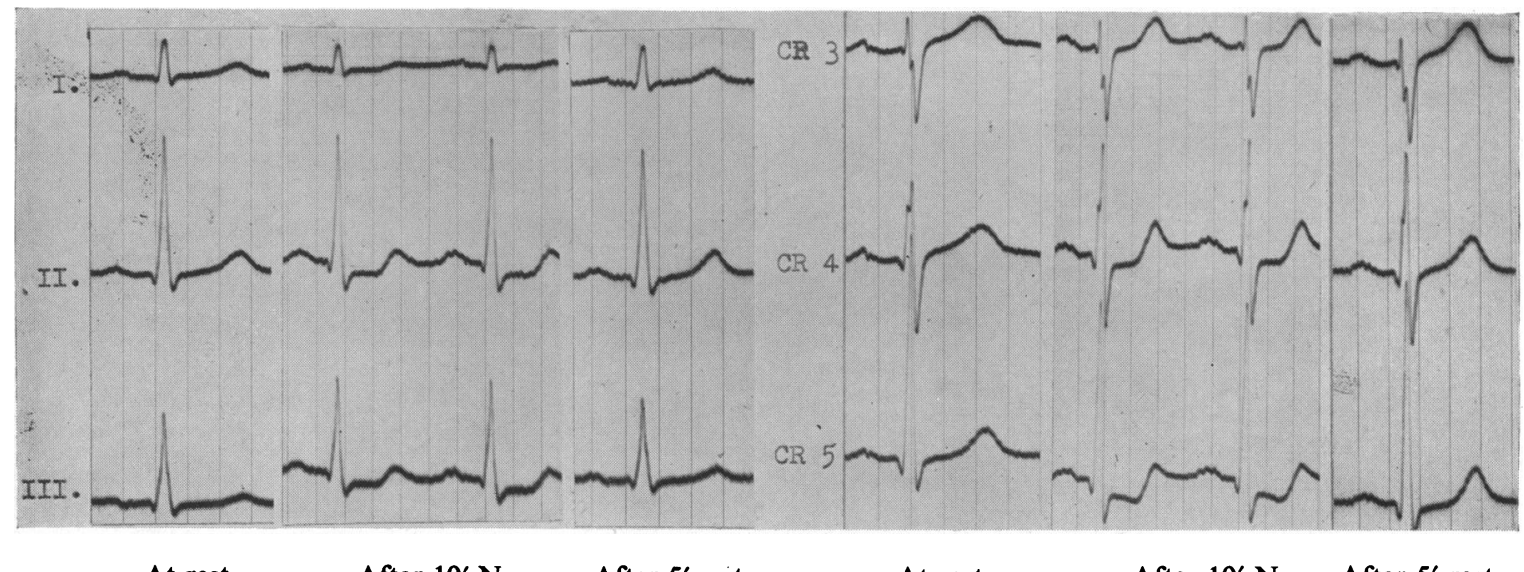

At rest

After $10^{\prime} \mathrm{N}_{2} \quad$ After $5^{\prime}$ rest.

At rest.

After $10^{\prime} \mathrm{N}_{2}$. After $5^{\prime}$ rest.

Fig. 3.-Case 21. Positive anoxæmic test. Total S-T depression $6 \frac{1}{2} \mathrm{~mm}$.

Case 12. A woman, aged 55. Rheumatic aortic incompetence. Retrosternal and left mammary pain not closely related to exertion and with varying characteristics. An exceedingly neurotic woman, whose pain was difficult to assess. Resting cardiograms within normal range. Positive anoxæmic test (total S-T depression $=7 \mathrm{~mm}$. Fig. 4; Case 12).

Case 30. A man, aged 50. Myocardial infarction two years previously followed by left lower chest pain related to walking but unrelated to other heavy physical exertion. Pain also had other atypical features.

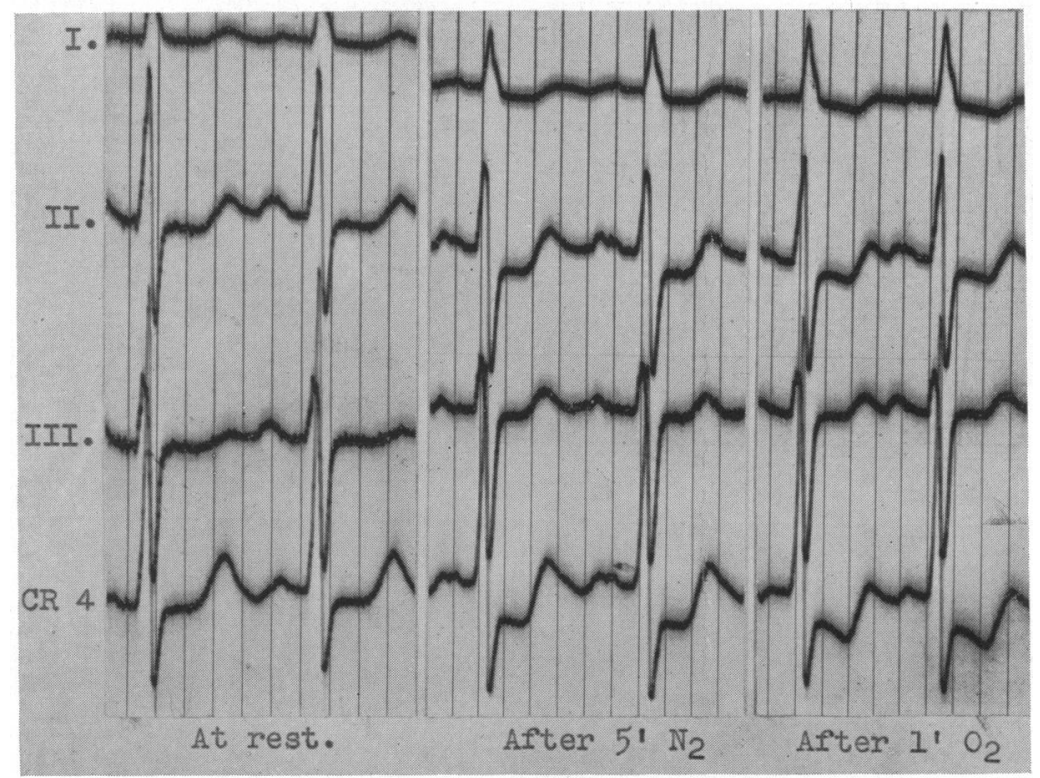

FIG. 4.-Case 12. Positive anoxæmic test. Total S-T depression $7 \mathrm{~mm}$. 
Clinical and X-ray examinations negative. Resting cardiograms showed healed posterior myocardial infarction. Positive anoxic test (total S-T depression $=5 \mathrm{~mm}$. Fig. 5 ; Case 30) indicating that his pain was still due to myocardial ischæmia. Died suddenly two months later. No post mortem.

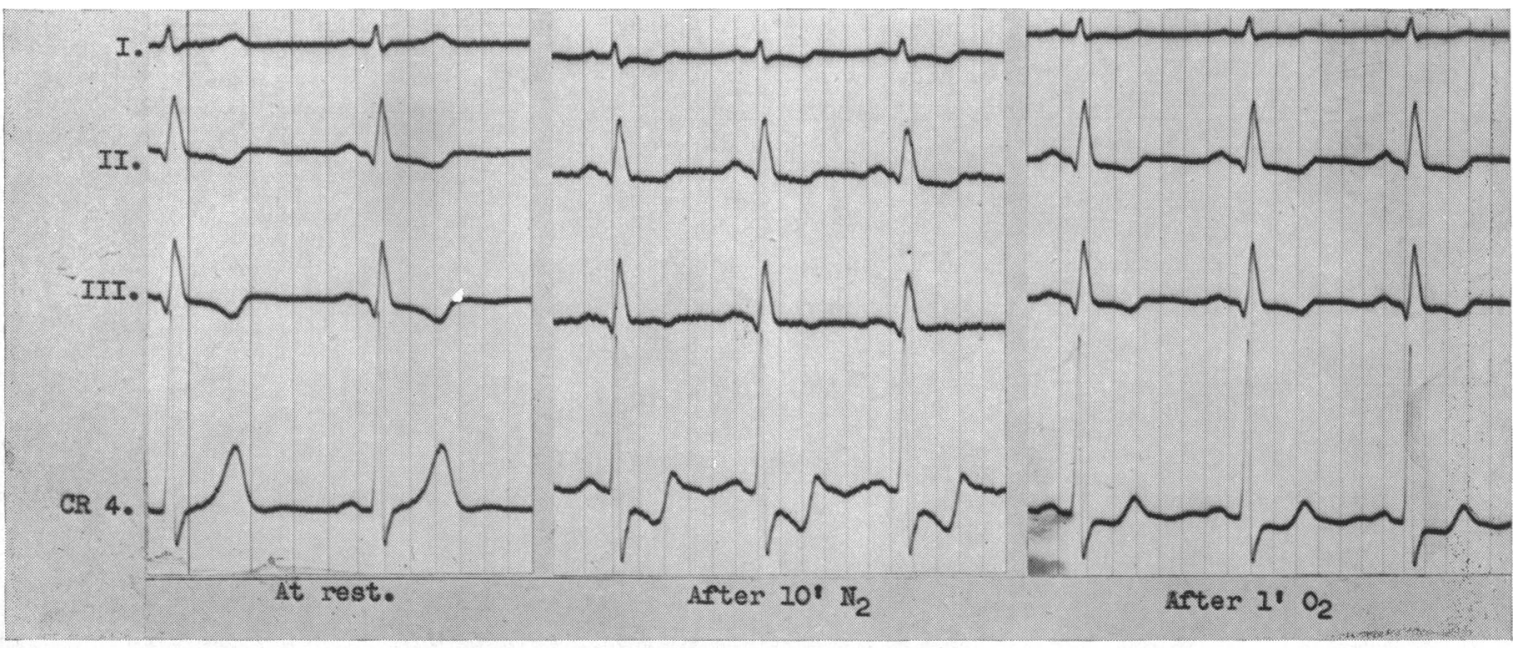

FIg 5.-Case 30. Positive anoxæmic test: total S-T depression $5 \mathrm{~mm}$.

Case 25. A woman, aged 68, gave a twelve-month history of retrosternal burning pain frequently coming on at rest in bed, but sometimes related to exertion. Not immediately relieved by trinitrin. Hiatus hernia was suspected, but excluded. Physical examination and screening of the heart were negative, apart from the finding of obesity and a high diaphragm. Resting cardiograms showed only a QIIITIII pattern which disappeared on deep inspiration and hence was not considered to signify myocardial infarction. Anoxæmic test was positive and confirmed the diagnosis (total S-T depression $=4 \frac{1}{2} \mathrm{~mm}$ ) (Fig. 6).
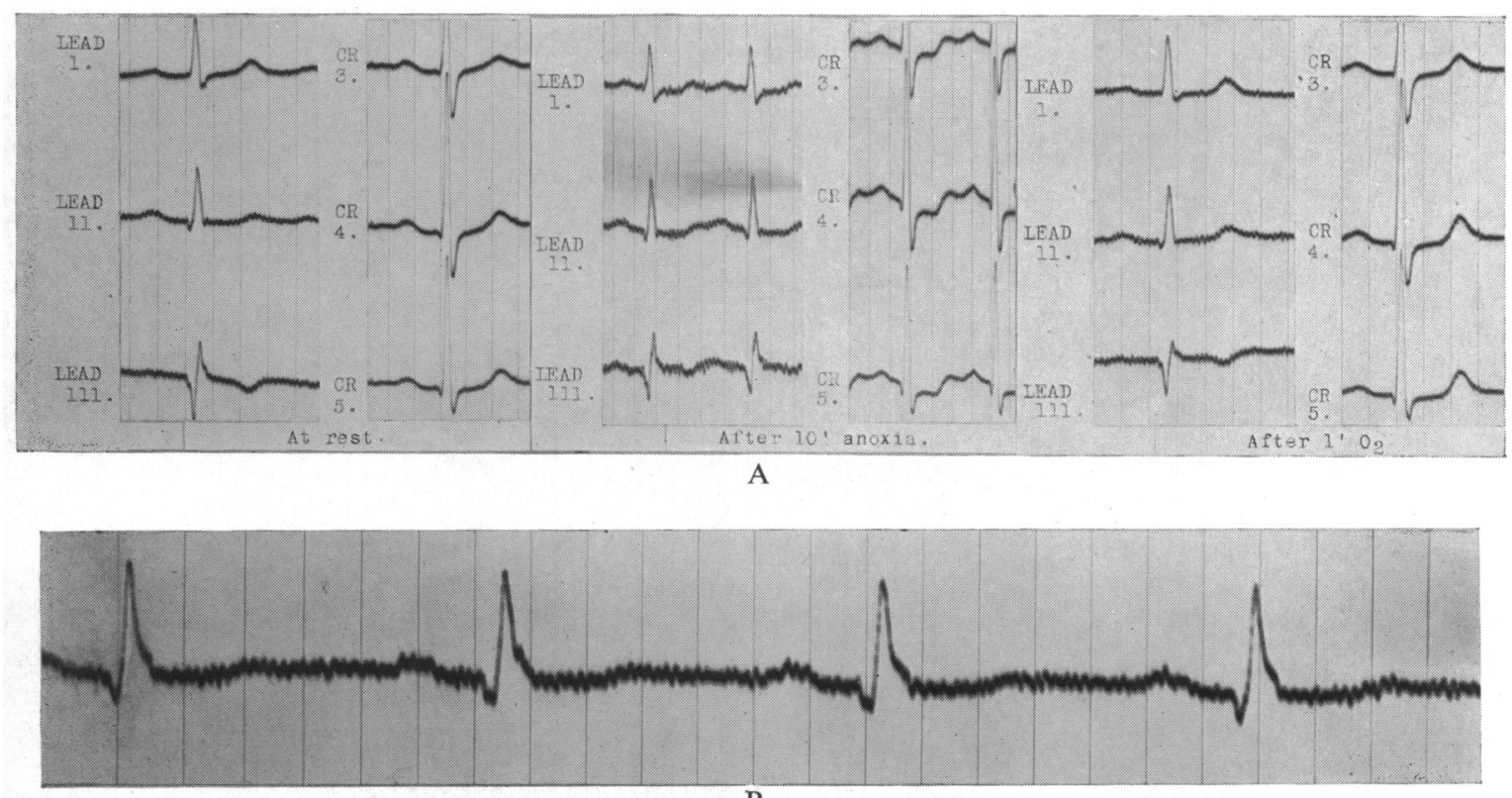

Fig. 6. Case 25. (A) Positive anoxæmic test: total S-T depression $=4 \frac{1}{2} \mathrm{~mm}$. (B) Lead III in full inspiration. 


\section{Discussion OF RESULTS}

What then is the potential value of the anoxæmic test? First, to try and confirm that a suspicious pain is in fact based on ischæmic heart disease. Secondly, to try to exclude angina pectoris as the cause of an atypical chest pain. Thirdly, to try to assess the degree of recovery following previous myocardial infarction. Fourthly, to help in deciding the fitness of a patient for a surgical operation and especially the anæsthetic. Fifthly, there is a possibility of assistance in assessing the value of drugs on the coronary circulation.

Information of some value and considerable interest has been obtained in about one-half of our cases. The series has been analysed but is hardly worthy of statistical presentation.

Instead of large numbers called from far and wide to make a big series we have studied, as carefully as possible, individual patients whom we knew well, as opportunity offered. Naturally such cases are not so very common. Each presented a real clinical problem and the information obtained was used in conjunction with the other evidence to come to a more definite opinion. On occasion we have used the test when some operation, not of an essential nature but yet advisable if there is no undue risk, is under consideration. A negative result has been taken as suggesting fitness for general anæsthesia. The anoxæmic test is not a reliable guide to prognosis.

With proper selection of patients and due precautions, the dangers of the test are minimal. It can be carried out in any hospital with average facilities. There is neither need nor justification for this procedure when the diagnosis has already been established or where no reasonable doubt exists. No patient should be submitted to it before a full series of electrocardiograms have been taken and examined; that is to say at least 9 leads consisting of 3 standard (or unipolar) limb leads and 6-7 chest leads. On a number of occasions when four leads have been normal we have found definite evidence of infarction on taking further leads. There is nothing new in this observation, of course, but it does emphasize the need for caution.

We are satisfied that further information of material value may be obtained in patients of the type under consideration. The criteria of abnormality vary only in degree from the changes seen in normal controls. It is difficult to draw a definite line between them. Consequently, there is a theoretical danger of false positive tests, that is, of attributing borderline cardiographic changes in healthy hearts to organic disease. Nevertheless, we have no reason to believe that we have ever been misled into diagnosing coronary disease when none was present. It is generally agreed that the present criteria of abnormality make such a mistake most unlikely. In borderline cases the test should be ignored.

An examination of our records reveals that the greatest abnormality is usually shown in a chest lead recorded over the left ventricle. In 9 out of 11 consecutive cases, the degree of S-T depression in lead IV is greater than that in any one of the three standard limb leads and indeed as great as, or greater than, in these three leads added together. Although further experience will be required to establish the point, it is suggested that S-T depression of $2 \mathrm{~mm}$. or more in lead IV indicates a positive test. We have recently been recording multiple chest leads and it seems probable that for routine purposes, Lead IV will prove to be the most suitable lead in that the degree of S-T depression is usually as much as, or more than, in any other lead. Furthermore, in the last eight cases recorded, the changes in unipolar (V) leads and bipolar (CR) chest leads have been compared. In seven of them, the degree of $S-T$ depression in CR leads has been significantly greater than in V leads. This too suggests a possible improvement and simplification in establishing criteria of abnormality.

These points are illustrated in Fig. 6. The limb leads are not in fact quite normal in that there is slight slurring of the QRS complex in Lead II. However, this is not diagnostic of coronary disease. It will be seen that the test is a positive one and the degree of S-T depression is greater in Lead IV than in the three limb leads added together and greater in CR4 than in V4.

\section{THEORETICAL ASPECTS}

Changes in the $\mathrm{S}-\mathrm{T}$ segment and $\mathrm{T}$ waves similar to those occurring in the anoxæmic test though less marked, may be produced in healthy people by a variety of factors including emotion. In 
spite of this, assistance of real value may be given in clinical problems concerning coronary insufficiency. Obviously it is important to consider the relevant factors that may be operative during the test and also the theoretical background for the electrocardiographic changes observed.

Although the ultimate causes of the potential variations responsible for the changes remain largely a mystery the possible factors that initiate them are of practical importance. Our present problem is to distinguish the physiological variants which may occur during the test in normal people from pathological effects which may be seen in subjects with coronary artery disease. For this reason reference must be made to some of these factors which include anoxæmia, ischæmia, emotion, tachycardia, hyperventilation, alkalosis, posture and autonomic imbalance. They are often inter-related.

Other factors which can produce changes in the electrocardiogram should be remembered, e.g. a recent meal (Gardberg and Olsen, 1933; Simonson et al., 1946), an ice-cold drink (Wilson and Finch, 1923), tobacco (Graybiel et al., 1938; Bryant and Wood, 1947), need not be discussed here since they are normally excluded from playing any part during the test.

The changes produced by anoxæmia can be reversed by giving oxygen. The normal heart is remarkably tolerant to anoxæmia partly because of the marked increase in coronary blood flow which occurs though naturally this is limited in subjects with narrowed vessels. The cardiac output is also increased so that if the work of the heart is augmented there may yet be a relative myocardial ischæmia as in the exercise test (Wiggers, 1941). The changes produced by ischæmia are firmly established and similar in type to those under consideration.

Tachycardia, hyperventilation and autonomic imbalance with predominant sympathetic stimulation may all be responsible for the electrocardiographic changes produced by emotion. The effects of tachycardia are usually inseparable from the sympathetic overactivity and lowering or even inversion of the $T$ waves is known to accompany considerable tachycardia from any cause (White et al., 1941). However, tachycardia of sufficient degree does not occur in the anoxæmic test.

Hyperventilation may be responsible for some of the clinical manifestations in anxiety states (Kerr et al., 1937, 1939). Weakness, dizziness, faintness, parathesiae, tachycardia, tremulousness and cramps can be produced by voluntary over-breathing and Thompson (1943) also states that pain simulating angina pectoris may be reproduced in healthy persons and that symptoms may be accompanied by $T$ wave inversion and slight S-T segment depression in the electrocardiogram. Alkalosis is probably the principal but not the sole factor concerned in such cases. Similar changes have been recorded when alkalosis results from other causes (Lawrence and Allott, 1943; Barker et al., 1939). Some degree of hyperventilation is commonly observed during the anoxæmic test but is usually slight and not sufficient to affect the electrocardiogram. It is in fact more likely to occur during the exercise test.

The effects of posture in lowering or inverting the $T$ wave are now well known though there have been varying opinions about the mechanism involved (Leimdörfer, 1935; Åkesson, 1936; Graybiel and White, 1935; White et al., 1941; Scherf and Weisberg, 1941; Master, 1944; Wendkos, 1944; Wendkos and Logue, 1946). This factor was avoided in our cases by taking all records with the subject recumbent.

Autonomic imbalance is presumably responsible for similar changes (of lesser degree) which have sometimes been observed in cases of effort syndrome. Sympathetic stimulation which can be neutralized by giving a sympatholytic drug can produce such changes even in the absence of significant tachycardia (Wendkos and Logue, 1946).

\section{Discussion}

It is clear that flattening or inversion of the $T$ waves may occur under such a wide range of circumstances that it is an unreliable sign of coronary insufficiency in the anoxæmic or exercise tests. More attention can be paid to S-T depression although it may also occur in some of the circumstances in which $T$ wave changes are seen. However, from a study of the papers which have been published the significance of S-T depression is largely substantiated and with Levy's method of adding up the total depression in the four leads, a reasonably clear border line between normal and abnormal cases can be drawn. Where the results are near the border line due caution in interpretation is naturally indicated. Usually, however, the test will be either clearly positive or negative. Discussion of the principles of electrocardiographic interpretation involved may be 
found in the reviews of Wilson (1944, 1947), Ashman (1940), Eyster and Meek (1942), Bayley (1943, 1946), Katz (1947), Hellerstein and Katz (1948), Pirani and Schlichter (1946) and Price and Janes (1943). In experimental animals (Bayley et al., 1944) temporary myocardial ischæmia has been shown to produce changes in the $\mathrm{S}-\mathrm{T}$ segment and $\mathrm{T}$ waves similar to those observed in the anoxæmic test.

In cardiac infarction S-T displacement is usually upwards but it is commonly downwards both in spontaneous angina and in the anoxæmic test. For these differences good reasons may be advanced. It is known that injury to the sub-epicardial layers will result in upward displacement of the S-T segment as recorded by an overlying electrode and injury to the sub-endocardial in downward displacement. This has been demonstrated in animals and also observed in human myocardial infarction. Also an injury to the sub-epicardial region will result in greater and more persistent electrocardiographic changes than a similar injury to the sub-endocardial region (Hellerstein and Katz, 1948). In the experimental work as in naturally occurring myocardial infarction a layer of sub-endocardial muscle commonly survives and accounts for the fact that the $S-T$ displacement is upwards. The reason for this frequent immunity of the sub-endocardial lamina presumably lies in relatively better nutrition which derives from the collateral blood supply of the sub-endocardial arteriolar plexus of Gross, from the Thebesian vessels and possibly from direct diffusion of oxygen through the endocardial wall from the ventricular cavity. In spontaneous attacks of angina the S-T displacement which is usually seen may be explained by spasm of the sub-endocardial plexus (Bayley, 1946). In the anoxæmic test not only is the blood in the coronary vessels and ventricular cavities inevitably reduced in oxygen content so that there will be little benefit to the sub-endocardial layers but it may be that the latter are abnormally sensitive to oxygen lack since they are accustomed to a superior blood supply (Biörck, 1948).

The theoretical basis for the anoxæmic test is nevertheless not fully established. S-T depression may be caused by physiological changes concerning repolarization or by pathological changes leading to the production of a current of injury. Fortunately, electrocardiograms can usually be interpreted without regard to theory and failure to agree upon, or even understand, the underlying mechanisms has not prevented progress in this field.

\section{SUMmaRY AND CONCLUSIONS}

Various procedures which have been recommended for the assessment of coronary insufficiency are briefly reviewed and the history of the anoxæmic test is referred to in some detail. The technique of the anoxæmic test is described and criteria of abnormality and possible reactions discussed. It is suggested that the duration of anoxæmia can be limited to ten minutes. The results of 22 control tests and a study of 33 patients are presented. Assistance of material value may be obtained in difficult cases particularly with regard to atypical pain in the chest. When properly conducted on suitable patients the test is not dangerous.

It is suggested that $\mathrm{S}-\mathrm{T}$ depression of $2 \mathrm{~mm}$. or more in Lead IV indicates a positive test and that further experience may show that it is unnecessary to record other leads.

It is concluded that the anoxæmic test has a small but useful role to play in the assessment of coronary insufficiency and holds certain advantages over the exercise test.

We should like to acknowledge the considerable help received from members of the Anæsthetic Staff of the Western General Hospital, and also to the physicians who have referred their cases.

\section{REFERENCES}

Åkesson, S. (1936). Upsala Läkaref Forh, 42, 263. (Quoted by White, P. E., et al. (1941). Brit. Heart J., 3, 233). Ashman, R., Wilde, W. S., and Drawec, E. (1940). Amer.J. Physiol., 128, 547.

Barker, P. S., Schrader, E. L., and Ronzoni, E. (1939). Amer. Heart J., 17, 169.

Bayley, R. H. (1943). Amer. Heart J., 26, 769.

(1946). Amer. Heart J., 31, 677.

_, La Due, J. S., and Yorke, D. J. (1944). Amer. Heart J., 27, 164 and 657.

$2 \mathrm{~N}$ 
Biörck, G. (1946a). Amer. Heart J., 32, 689.

(1946b). Brit. Heart J., 8, 17.

, Jackson, F. S., and Rohlin, A. (1948). Acta. Med. Scand., 82, 283.

Bryant, J. M., and Wood, J. E. (1947). Amer. Heart J., 34, 20.

Burchell, H. B., Pruitt, R. D., and Barnes, A. R. (1948). Amer. Heart J., 36, 373.

Burnett, C. T., Nimms, M. G., and Josephson, C. J. (1942). Amer. Heart J., 23, 306.

Cottrel, J. E., and Wood, F. C. (1931). Amer. J. med. Sci., 181, 36.

Dripps, R. D., and Comroe, J. H. (1947). Amer. J. Physiol., 149, 277.

Evans, C., and Bourne, G. (1940). Brit. Heart J., 3, 69.

Eyster, J. A. E., and Meek, W. J. (1942). Amer. J. Physiol., 138, 166.

Gardberg, M., and Olsen, F. (1933). Amer. Heart J., 17, 725.

Graybiel, A., and White, P. D. (1935). Amer. Heant J., 10, 345.

- Starr, R. S., and White, P. D. (1938). Amer. Heart J., 15, 89.

Greene, C. W., and Gilbert, N. C. (1921). Arch. intern. Med., 27, 517.

Grossman, M., Weinstein, W. W., and Katz, L. N. (1949). Ann. intern. Med., 30, 387.

Hellerstein, H. K., and Katz, L. N. (1948). Amer. Heart J., 36, 184.

Katz, L. N. (1947). Physiol. Rev., 27, 398.

—, Hamburger, W. W., and Lev, H. (1932). Amer. Heart J., 7, 371.

- - - - and Schutz, W. J. (1934). Amer. Heart J., 9, 771.

Kerr, W. J., Dalton, J. W. and Gliebe, P. A. (1937). Ann. intern. Med., 11, 961.

, Soley, M. H., and Shock, N. W. (1939). J. Amer. med. Ass., 113, 637.

Kountz, W. B., and Gruber, C. M. (1929). Proc. Soc. Exper. Biol. Med., 27, 171.

Larsen, K. H. (1938). Copenhagen, Ejnar Mundsgaards Forlag. (Quoted by Levy, 1941a).

Lawrence, J. S., and Allott, E. M. (1943). Brit. Heart J., 5, 128.

Leimdörfer, A. (1935). Med. Klin., 31, 1536. (Quoted by White, P. D., et al. (1941). Brit. Heart J., 3, 233).

Levine, S. A., Ernstene, A. C., and Jacobson, B. M. (1930). Arch intern. Med., 45, 191.

Levy, R. L. (1946). Modern Concepts of Cardiovascular Disease, 15, No. 4.

1 , Barach, A. L., and Bruen, H. G. (1938). Amer. Heart J., 15, 187.

-, Bruen, H. G., and Russell, N. G. (1939). Amer. J. med. Sci., 197, 241.

- - Patterson, J. E., Clark, T. W., and Bruen, H. G. (1941b). J. Amer. med. Ass., 117, 2113.

, Williams, N. E., Bruen, H. G., and Carr, H. A. (1941a). Amer. Heart J., 21, 634.

Malmström, A. (1947). Acta Physiol. Scand., 125, suppl. 195.

Mannheimer, E. (1946). J. Pediatrics., 29, 1.

, and Carlgren, L. E. (1948). J. Pediatrics., 33, 1.

Master, A. M., Friedman, R., and Dack, S. (1942). Amer. Heart J., 24, 777.

- , Nuzie, S., Brown, R. C., and Parker, R. C. (1944). Amer. J. med. Sci., 207, 435.

Nylin, G. (1943). Nordisk. Med., 18, 1045. (Quoted by Biörck, 1946).

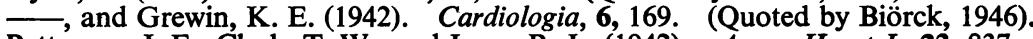

Patterson, J. E., Clark, T. W., and Levy, R. L. (1942). Amer. Heart J., 23, 837.

Penneys, R., and Thomas, C. B. (1948). Bull. Johns Hopkins Hosp., 82, 470.

Pirani, C. L., and Schlichter, J. G., (1946). Ann. intern. Med., $25,847$.

Price, R. K., and Janes, L. R. (1943). Brit. Heart J., 5, 134.

Resnik, W. H. (1925). J. Clin. Invest., 2, pp. 93, 117 and 125.

Riseman, J. E. F., Waller, J. V., and Brown, M. G. (1940). Amer. Heart J., 19, 683.

Rothschild, M. A., and Kissin, M. (1933). Amer. Heart J., 8, pp. 729 and 745.

Ruskin, A. (1947). Amer. Heart J., 34, 569.

Scherf, D., and Weisberg, J. (1941). Amer. J. mea. Sci., 201, 693.

Simonson, E., Alexander, H., Henschel, A., and Keys, A. (1946). Amer. Heart J., 32, 202.

Stewart, H. J., Horger, E. L., and Sorenson, C. W. (1948). Amer. Heart J., 36, 161.

Thompson, W. P. (1943). Amer. Heart J., 25, 372.

Ward, G. E. S., and Wright, S. (1929). Lancet, 2, 1184.

Weintraub, H. J., and Bishop, L. F. (1947). Ann. intern. Med., 26, 741.

Wendkos, M. H. (1944). Amer. Heart J., 28, 549. , and Logue (1946). Amer. Heart J., 31, 711.

White, P. D., Chamberlain, E. L., and Graybiel, A. (1941). Brit. Heart J., 3, 233.

Wiggers, C. (1941). Ann. intern. Med., 14, 1237.

Wilson, F. N., and Finch, R. (1923). Heart, 10, 275. , Johnston, F. D., Rosenbaum, F. F., Erlanger, M., Kossman, C. E., Hecht, H., Kotrim, N., de Oliveira, R., and Barker, D. S. (1944). Amer. Heart J., 27, 19.

_. Rosenbaum, F. F., and Johnston, F. D. (1947). Advances in Internal Medicine, $2,52$. 